\title{
Koch Island Fractal Patch Antenna (KIFPA) for Wideband Applications
}

\author{
Meryem HADJI, Sidi Mohammed MERIAH, Djamila ZIANI \\ Laboratory of Telecom of Tlemcen LTT, \\ Department of Telecom, \\ University of Tlemcen, ALGERIA
}

\begin{abstract}
In this paper, a new modified printed Koch Island Fractal Patch Antenna (KIFPA) is studied. The conception of such antenna is based on the combination of different techniques. The first, concerns the fractal geometry of the patch, while the second comprises modified ground-plane. The patch is etched according to Koch Island geometry with different iteration number ( $\mathrm{n}=1,2$ and 3 ) as inductive loading. It is proximity fed by a $50 \Omega$ micro strip line. The proposed antenna operates in the frequency band [6.03-12.62 GHz] with $70.7 \%$ for $S 11 \leq-10 \mathrm{~dB}$. The antenna gain and radiation patterns within the operating band are simulated. The design was performed using the CST Microwave Studio Software and the results are presented, compared and discussed. Finally, the proposed antenna is fabricated and the reflection coefficient parameter is measured to validate simulation results.
\end{abstract}

Keywords-Fractal antenna; Koch Island fractal-shape; microstrip patch antenna; wideband antenna

\section{INTRODUCTION}

Nowadays, with the emergence of wireless communication technology and growing interest on their applications, several fractals have been widely deployed in antenna designs, due to the significant improvements added to their characteristics performance.

The theory of "Fractal" was first defined by Benoit Mandelbrot in 1975 [1], which was derived from the latin word "fractus", signifying "broken" or "fractured". The idea behind it was to describe nature's geometry and classify complex geometries that were generated with an iterative procedure [2], whose dimensions were not whole numbers.

The concept of fractal geometry is very requested in the field of antenna design. For instance, the space filling properties of Giuseppe Peano [3] and Minkowski [4] fractals have been exploited for the miniaturization. While, the selfsimilarity property of Koch [5], Sierpinski [6], Minkowski [7] and circular fractal shape [8] can be used to resonate the antenna at a number of frequency bands to obtain multi-band behavior. Fractals proprieties are also investigated in [9] and [10 -11] to obtain various kinds of wide band and ultra-wide band antennas respectively.

In this paper, we propose a new wideband fractal patch antenna for $\mathrm{X}$ band applications.

\section{A. Related Work}

The obvious development of wireless communication applications requires a growing need for wide band and low profile antennas. In this context many examples clearly illustrate the importance of this kind of antenna.

In the literature, several methods are suggested to improve the antenna bandwidth such as, a printed $\Gamma$-shape Fractal Antenna [12]; A Spidron and Giusepe Peano fractal slot antenna studied in [13] and [14], respectively; a combination of two fractal geometries (Koch-Minkowski and Koch-Koch) along with the slot of a rectangular printed patch antenna with partial ground plane [15]; a coaxial feeding technique of modified printed square antenna [16]; a printed U-shape antenna on a circular ground plane with an inverted U-shape slot [17]; a defected ground plane using CPW feeding technique with modified and octagonal fractal patch proposed in [18] and [19], respectively.

Consequently, during our research, we are going to focus, explore, and investigate the wide band fractal patch antenna with modified ground plane.

\section{B. Contributions}

In this study, a new type of printed fractal modify Koch Island patch antenna is proposed. The printed patch of the final designed structure is obtained from the third iteration of the half Koch fractal. Also, the ground plane is modified by inserting small steps. So the final proposed antenna is characterized by:

- Wide impedance bandwidth with the same direction of radiation which is suitable for wideband applications.

- Small size, lower profile and easy to fabricate.

A comprehensive parametric study has been carried out to understand the effects of various Fractal Iteration Number parameters in order to achieve the best performance possible of the final antenna with modified ground-plane. Good impedance bandwidth covering 6.03-12.62 $\mathrm{GHz}$ frequency band (determined from $-10 \mathrm{~dB}$ return loss) used for $\mathrm{X}$-band applications is achieved. The simulations results are performed using CST Microwave Studio software [20]. Thereafter experimental results are obtained for the third iteration order antenna for comparison. 


\section{DESCRIPTION OF THE PROPOSED ANTENNA}

Fractal shaped antennas present very important characteristics which are related to the geometrical properties. The Koch fractal appeared in 1904 by the Swedish mathematician Helge von Koch [21]. It is a simple example of a fractal structures used to reduce the antenna dimensions and enhance bandwidth performance, due to the increase of the effective electronic length.

It is characterized by two important parameters that are the Iteration Factor and the Iteration number.

The Iteration Factor specifies the process rule of fractal structure generation, in this case $\mathrm{IF}=1 / 3$ whereas the Iteration number describes how iterative processes are performed. When the number of iteration is zero, we have an equilateral triangle called the fractal generator as shown in Fig. 1. But if the iteration number converges to infinity meaning the process is executed an infinity of times, the Koch snowflake fractal is achieved [22].

The Koch Island is used in this antenna owing to the selfsimilarity property, the structure conserves the same form for any step as shown in Fig. 2(a). $\mathrm{R}$ is the radius of a circle which covers the entire fractal shape. So a large surface area is bounded by a circle of fixed radius R. Fig. 2(a) present the Koch Island fractal generated by equilateral triangle at the third iteration. More, the circular patch presents a very interesting characteristic for wide band applications compared to other structures.

Whereas, in our work, the antenna structure consists only of the half third iterative Koch Island patch generated from an equilateral triangle of side $\mathrm{a}=11.5 \mathrm{~mm}$ which is very similar to that of a semi-circle patch studied in [23] and modified partial ground plane.

The construction of the designed final antenna structure is illustrated in Fig. 2(b). The antenna is printed on a $1.6 \mathrm{~mm}-$ thickness FR4 dielectric substrate of dimensions $30 \times 30 \mathrm{~mm}^{2}$ and relative permittivity 4.4 . Where, a patch is placed co-planar with finite modified rectangular ground plane with size of $\mathrm{GL}=10 \mathrm{~mm}$ and $\mathrm{GW}=30 \mathrm{~mm}$. The separation distance between the patch and the ground is $\mathrm{d}=2 \mathrm{~mm}$. A $50 \Omega$ SMA connector is used for feeding the Koch patch antenna through the microstrip line section which is printed on the opposite side.

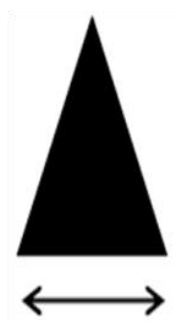

a

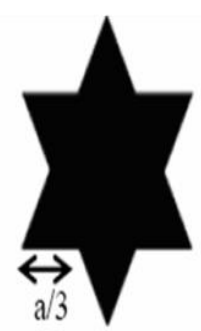

Fig. 1. Koch Island generation processing.

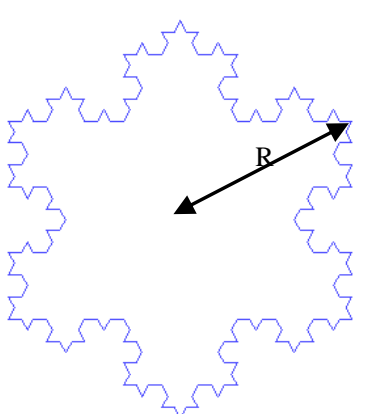

(a)

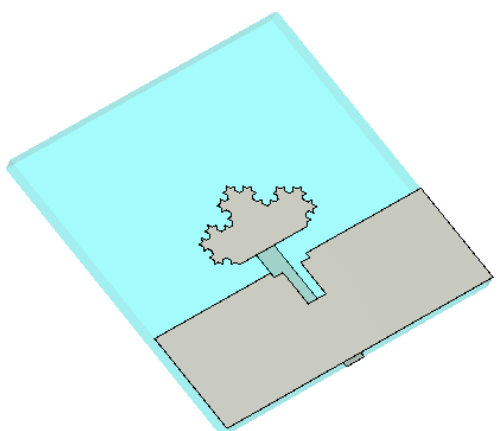

(b)
Fig. 2. (a) Koch fractal geometries; (b) Design of the proposed final antenna.

\section{Simulation AND MEASUREMENT RESUlS}

Initially, several different shapes for the patch antenna with simple ground plane were used. But in order to improve bandwidth characteristics; it was found that a patch and an optimized geometry of the whole structure gives the best possible results.

\section{A. Effects of Iteration Number ( $n)$}

In order to see the effect of the variation of the iteration number $\mathrm{n}$ on the band width performance, the structures with Iteration Factor $\mathrm{IF}=1 / 3$ and different $\mathrm{n}=1,2$ and 3 for antenna1, antenna 2 and antenna 3 respectively as shown in Fig. 3 were simulated by CST Microwave Studio electromagnetic simulator.

Fig. 4 illustrates the reflection coefficient S11 comparison against the frequency of the designed antenna structures for the three iterations numbers presented in Fig. 3. It can be shown that for antenna1, dual operating bands $6.08-7.57 \mathrm{GHz}$ and $8.74-12.23 \mathrm{GHz}$ with respect to $-10 \mathrm{~dB}$ are obtained. For the antenna 2 and antenna 3 with iteration number 2 and 3 respectively, the central frequency $f r l$ and $f r 2$ of the lower and higher frequency bands got shifted toward lower frequency. We can also observe that for the structure 3, the two operating bands obtained $6.00-7.71 \mathrm{GHz}$ and $8.17-12.55 \mathrm{GHz}$ are more important than that of the antenna1 and antenna2. However, it entails degradation for level bandwidth adaptation for higher frequencies. This signifies that the impedance bandwidth is improved with increasing the number of iterations. But, owing to practical limitations and simulation results, the fourth iterative structure is not designed and simulated. Then, the antenna 3 described above was constructed for measurement use.

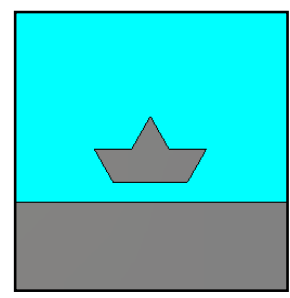

(a)

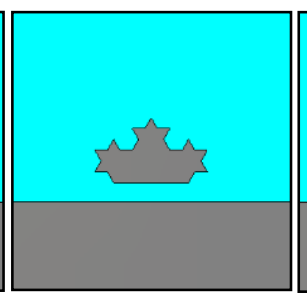

(b)

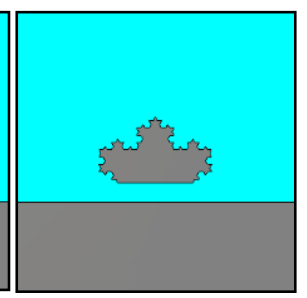

(c)
Fig. 3. Iterative Structures of the simulated antennas (a) Antenna 1; (b) Antenna 2; (c) Antenna 3. 


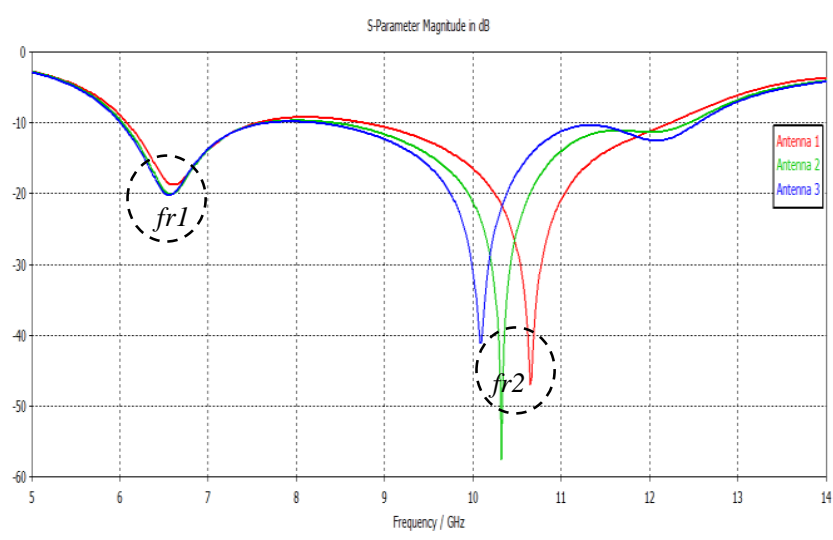

Fig. 4. Simulated Reflection coefficient versus frequency characteristics for iterative structures of designed antenna.

The fabricated prototype of the designed antenna structure is demonstrated in Fig. 5.

Fig. 6 shows the comparison between simulated and measured return loss for the proposed antenna 3. Good agreement can be observed. Exceptionally, for the frequency band $[5.24 \mathrm{GHz}-6.00 \mathrm{GHz}]$. The frequency drift is produced by the error in the manufacture and measurement. Measured impedance bandwidths for $-10 \mathrm{~dB}$ return loss of the two operating bands are $890 \mathrm{MHz}(5.94-6.83 \mathrm{GHz})$ and $4.8 \mathrm{GHz}$ $(9.06-13.86 \mathrm{GHz})$.

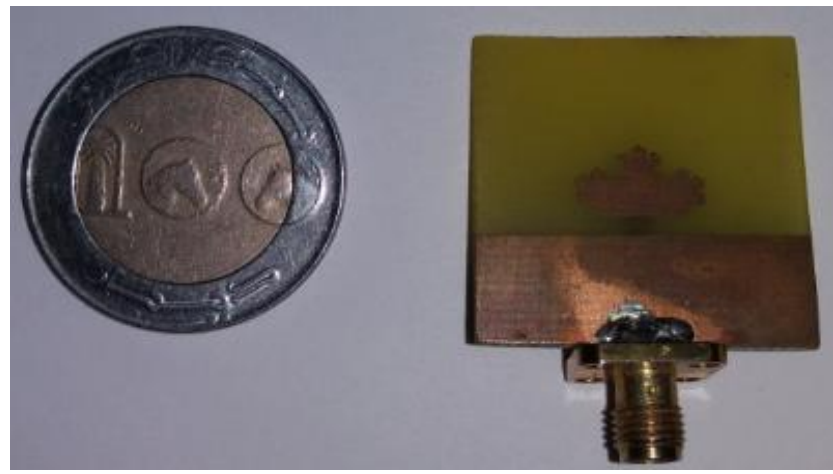

Fig. 5. Photograph of the antenna 3 fabricated prototype.

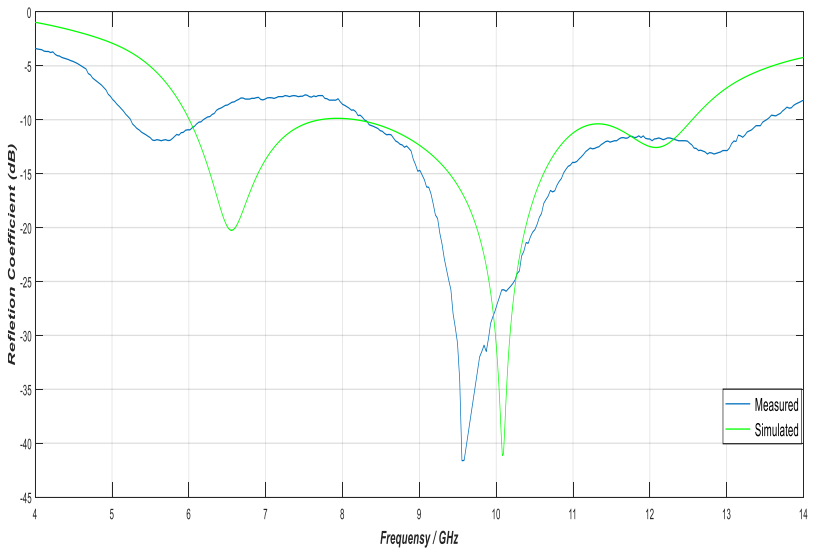

Fig. 6. Simulated and measured reflection coefficients of the proposed antenna 3 .
The simulated 3D radiation patterns of the designed antenna 3 structure at some frequency points are illustrated in Fig. 7. It shows acceptable stability of the radiation selected frequency antenna. While the simulated gain (Fig. 8) of the proposed antenna 3 against frequency band $[4 \mathrm{GHz}-14 \mathrm{GHz}]$ shows that the gain increases for higher frequencies. It is around $2.51 \mathrm{dBi}, 5.37 \mathrm{dBi}$ and $3.58 \mathrm{dBi}$ at $6.54 \mathrm{GHz}, 10.00 \mathrm{GHz}$ and $12.18 \mathrm{GHz}$, respectively.
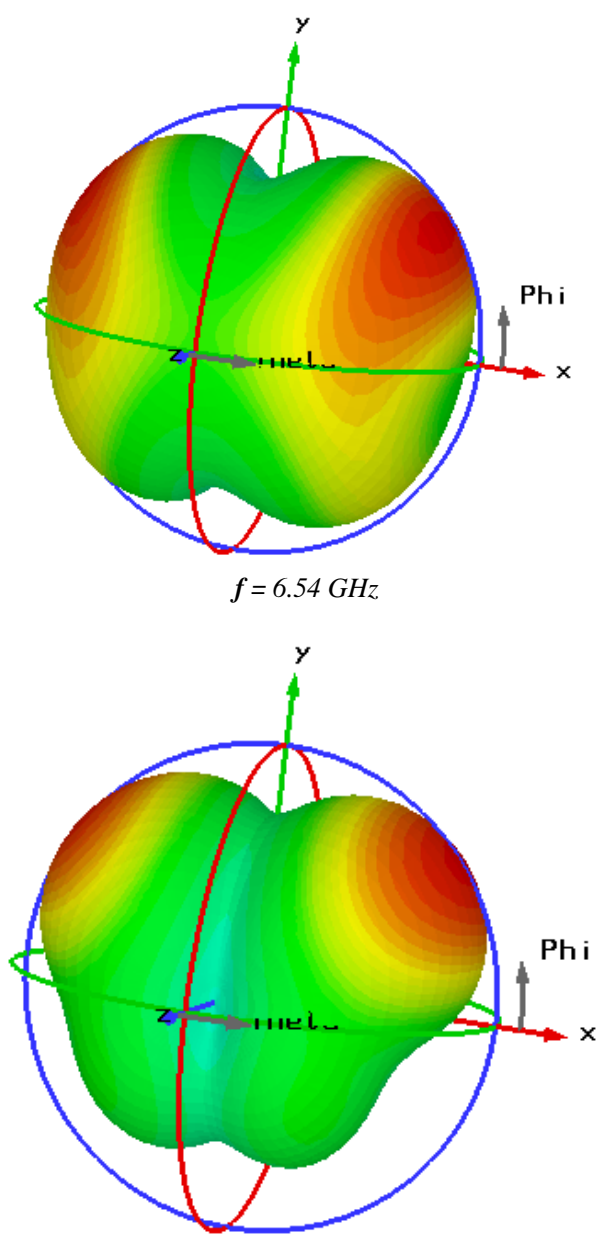

$f=10.07 \mathrm{GHz}$

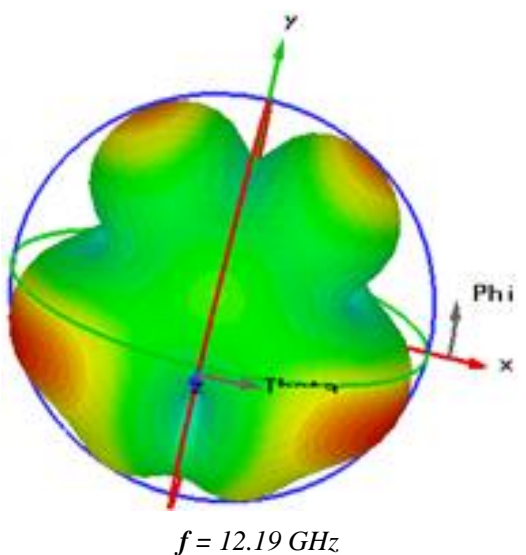

Fig. 7. Simulated 3D radiation patterns of the antenna 3 at some frequencies. 


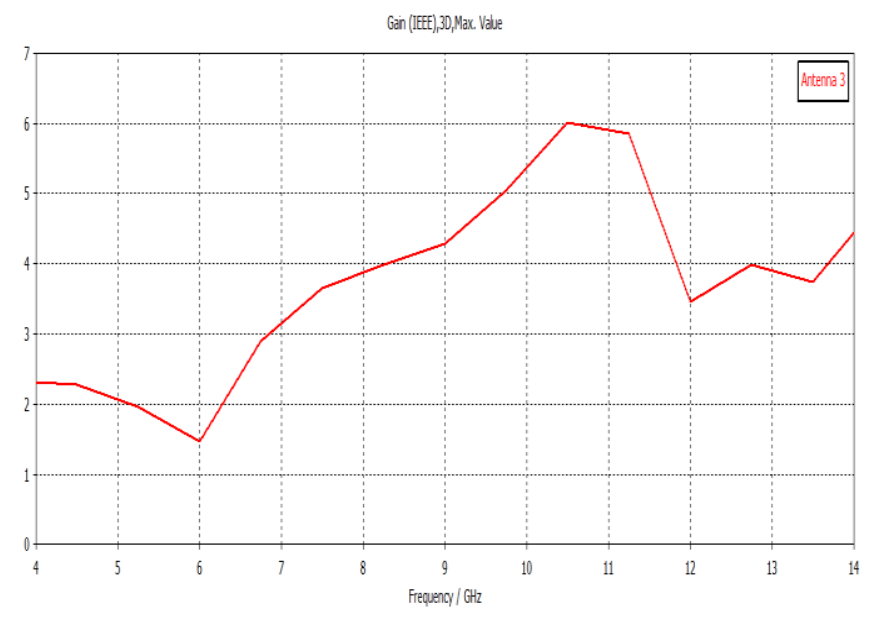

Fig. 8. Variation of simulated Gain in dBi against frequency for designed antenna 3.

\section{B. Effects of Ground Plane (GND)}

The rectangular partial ground plane used in the microstrip patch antenna design is one of the most important criteria. So, the modified ground plane has received much attention to ameliorate the antenna characteristics. This kind of study is presented in [24], [25].

The potential benefits of the proposed antenna 3 with the simple ground have been discussed previously. In this section the effects of inserting slots on the antenna 3 ground plane (GND) as shown in Fig. 9 are examined.

The comparison among the reflection coefficient characteristics of the antenna 3 with simple ground plane and finale proposed antenna 4 is presented in Fig. 10. It is observed that for antenna 4 which the ground plane is modified by inserting slots, the two operating antenna 3 bands got merged resulting into a wide operating band of $6.59 \mathrm{GHz}$ under the condition of $\mathrm{S} 11<-10 \mathrm{~dB}$, from $6.03 \mathrm{GHz}$ to $12.62 \mathrm{GHz}$ with $70.7 \%$. This signifies that the impedance matching improved over the entire band, enhancing the bandwidth of operation.

The final proposed antenna 4 with modified ground plane was constructed for measurement use. The photograph of prototype antenna is shown in Fig. 11.

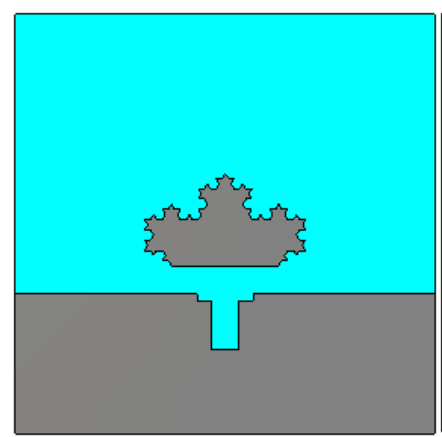

(a)

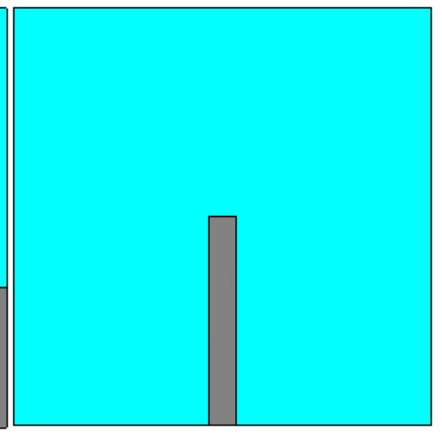

(b)
Fig. 9. Proposed final Koch Island antenna (Antenna 4) (a) Back view; (b) Front view.

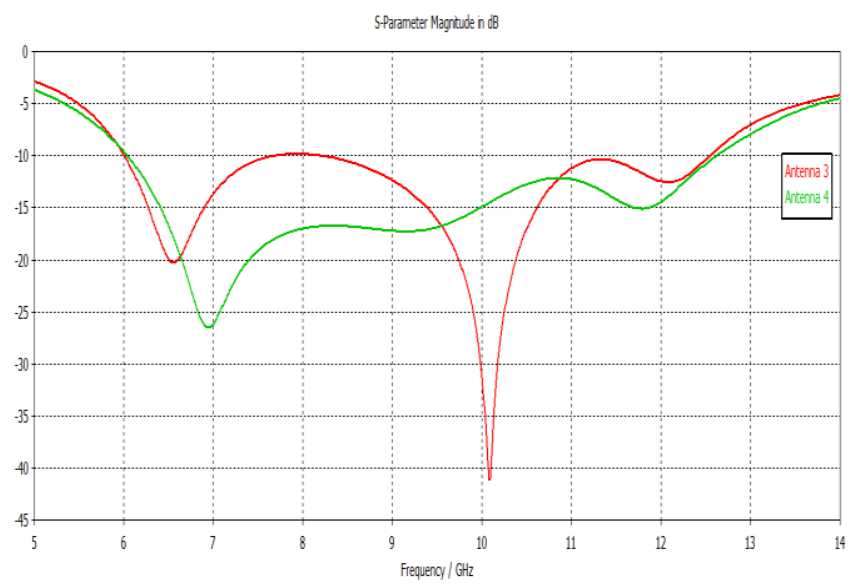

Fig. 10. Simulated reflection coefficient of antenna 3 with simple GND and Koch Island antenna 4 with modified GND.

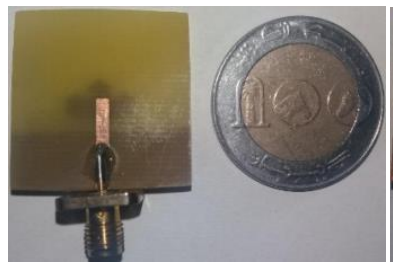

(a)

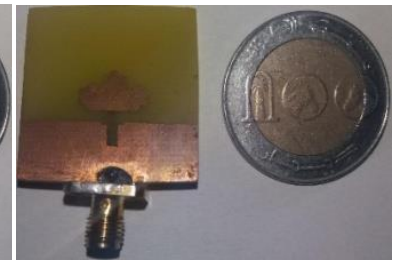

(b)
Fig. 11. Photograph of the antenna 4 fabricated prototype. (a) Front view; (b) Back view.

After the realization of the prototype of the proposed antenna 4, the input reflection coefficient is tested. The simulated and measured return loss against frequency of the proposed antenna 4design is plotted in Fig. 12, show good agreement. Measured reflection coefficient of this wide band antenna indicates that the $-10 \mathrm{~dB}$ operating bandwidth is 5.94 $\mathrm{GHz}$ extends on the interval $[6.03-11.97 \mathrm{GHz}]$. It is wide sufficient to cover the required bandwidths for $\mathrm{x}$ band [8 - 12 $\mathrm{GHz}$ ] applications. A difference in the adaptation level was observed between simulated and measured results. This is due to the fabrication inaccuracy and measurement conditions.

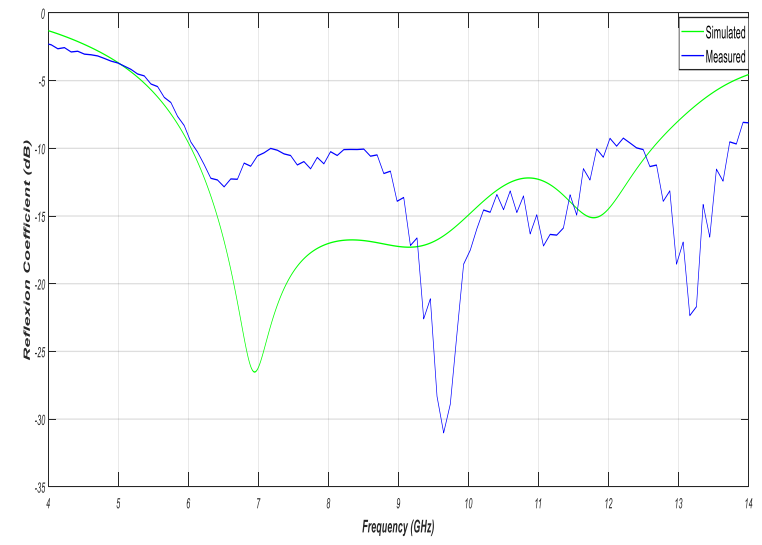

Fig. 12. Simulated and measured reflection coefficients of the final proposed antenna 4.

The simulated radiation patterns at different frequencies of the operating bandwidth shows that the antenna radiates in the 
same direction for all selected frequencies as presented in Fig. 13.

Fig. 14 illustrates the variation of the simulated gain versus the frequency interval $[5-14 \mathrm{GHz}]$. It is observed that the antenna gain is varying from a minimum of $1.5 \mathrm{dBi}$ for $6.03 \mathrm{GHz}$ to a maximum of $6.28 \mathrm{dBi}$ for $10.5 \mathrm{GHz}$ across the desired bandwidth.

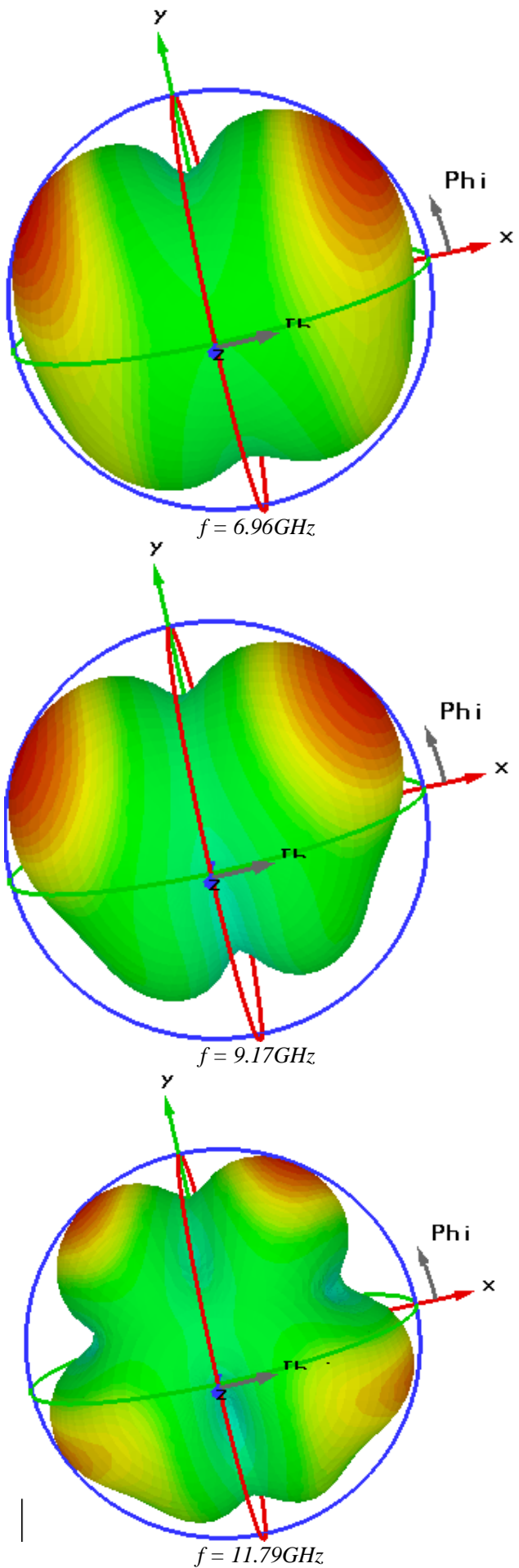

Fig. 13. Simulated 3D Radiation patterns of the proposed antenna 4 at some frequencies.

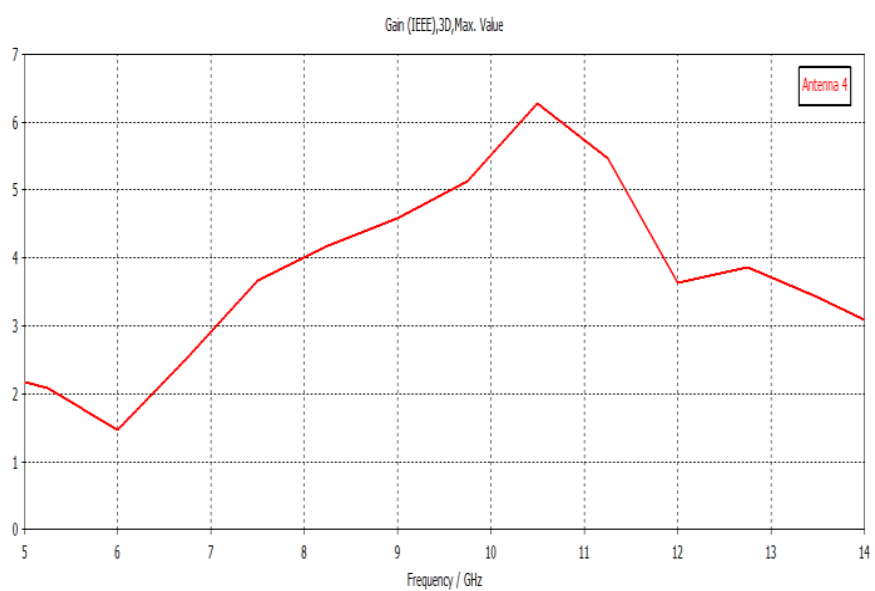

Fig. 14. Variation of simulated Gain in $\mathrm{dBi}$ against frequency for designed antenna 4

\section{CONCLUSION}

In this paper, a modified microstrip patch antenna KIFPA structure using the Koch Island fractal geometry for bandwidth enhancement is proposed. The effect of the patch iteration number and the modified ground plane are investigated. The application of Koch fractals to the patch and inserting slots to the simple rectangular partial ground plane are clearly significant in improving the antenna level adaptation performance, enhancing the operating bandwidth of the proposed final antenna. The computer simulations and measured results of the proposed antennas have shown good agreement.

\section{ACKNOWLEDGMENT}

The authors would like to gratefully acknowledge Pr. SALAH-BELKHODJA Faouzifrom Telecommunications and Digital Signal Processing Laboratory, University of SidiBelabbes for his technical support in providing the experimental data.

\section{REFERENCES}

[1] B. Mandelbrot, "The fractal geometry of nature", Freeman and Company, New York, 1975.

[2] K Falconer., Fractal Geometry: Mathematical foundations and applications, John Wiley and Sons, Chichester, 1990.

[3] H.Oraizi and S.Hedayati, "Miniaturization of Microstrip Antennas by the Novel Application of the Giuseppe Peano Fractal Geometries", IEEE Transactions on Antennas and Propagation, Vol. 60, No. 8, pp. 35593567, August 2012.

[4] I Putu Elba Duta Nugraha, I. Surjati, Syah Alam," Miniaturized Minkowski-Island Fractal Microstrip Antenna Fed by Proximity Coupling for Wireless Fidelity Application", TELKOMNIKA, Vol.15, No.3, pp. 1119-1126, September 2017.

[5] M.Hadji, S. M. Meriah and D. Ziani, “ A New Multi Band Microstrip Patch Fractal Antenna for WLAN/WIMAX Applications", Fifth International Conference on Image and Signal Processing and their Applications (ISPA), 2017.

[6] J. Anguera, E. Martínez, C. Puente, C. Borja, and J. Soler, "Broad-band dual-frequency microstrip patch antenna with modified Sierpinski fractal geometry," IEEE Transactions on Antennas and Propagation, vol. 52, no. 1, pp. 66-73, 2004.

[7] J. K. Ali, "A new reduced size multiband patch antenna structure based on Minkowski pre-fractal geometry," Journal of Engineering and Applied Sciences, vol. 2, pp. 1120-1124, 2007. 
[8] HuZhangfang, X.Wei, L.Yuan, HuYinping, Z.Yongxin,"Design of a modified circular-cut multiband fractal antenna", The Journal of China Universities of Posts and Telecommunications, Vol. 23, Issue 6, Pages 68-75, December 2016.

[9] M.NaghshvarianJahromi, A.Falahati, and Rob. M. Edwards, "Bandwidth and Impedance-Matching Enhancement of Fractal Monopole Antennas Using Compact Grounded Coplanar Wave guide", IEEE Transactions on Antennas and Propagation, Vol. 59, No. 7, pp. 2480-2487, July 2011.

[10] Y.K. Choukiker, S.K.Behera, "Modified Sierpinski square fractal antenna covering ultra-wide band application with band notch characteristics" ,IET Microwaves, Antennas \& Propagation, Vol. 8, Iss. 7, pp. 506-512, 2014.

[11] A.Kumar,"Designe of Fractal Antenna for Ultra Wide Band Applications", International Journal of Enginneering Research and Technology, IJERT, Vol. 4, Issue 07, pp. 541-544, July 2015.

[12] M. Ali. Dorostkara,b , R. Azima , M. T. Islama , " A Novel $\Gamma$-shape Fractal Antenna for Wideband Communications", The 4th International Conference on Electrical Engineering and Informatics (ICEEI ), pp. $1285-1291$.

[13] A. Altaf, Y. Yang, K.-Yoon Lee, ${ }^{2}$ and Keum Cheol Hwang, "Wideband Circularly Polarized Spidron Fractal Slot Antenna with an Embedded Patch", International Journal of Antennas and Propagation, April 2017.

[14] H. Oraizi and S. Hedayati, "A Novel Wide Slot Antenna Design using the Giusepe Peano Fractal Geometry", 20th Iranian Conference on Electrical Engineering, (ICEE2012), May 15-17, Tehran, Iran,2012.

[15] N.Sharma and V.Sharma, "A design of Microstrip Patch Antenna using hybrid fractal slot for wideband applications", Ain Shams Engineering Journal, July 2017.

[16] A. KhannaDinesh, K. SrivastavaJai and P. Saini," Bandwidth enhancement of modified square fractal microstrip patch antenna using gap-coupling", Engineering Science and Technology, an International
Journal, Vol18, Issue 2, Pages 286-293, June 2015.

[17] K.Mandal and P. P. Sarkar, " A Compact Low Profile Wideband UShape Antenna With Slotted Circular Ground Plane" ,AEU International Journal of Electronics and Communications, Volume 70, Issue 3, Pages 336-340, March 2016.

[18] R.Kumar and N.Kushwaha" Design And Investigation Of Sectoral Circular Disc Monopole Fractal Antenna And Its Backscattering", Engineering Science and Technology, an International Journal, Volume 20, Issue 1,PP. 18-27, February 2017, Pages 18-27.

[19] S. Singhal, A. Kumar Singh, "CPW-fed octagonal super-wideband fractal antenna with defected ground structure", IET Microwaves, Antennas \& Propagation, Volume: 11, Issue: 3, PP. 370-377, 2017

[20] CST Microwave Studio Suite 2014.

[21] M. Rani, R. Ul Haq, D. Kumar Verma," Variants of Koch curve", National Conference on Development of Reliable Information Systems, Techniques and Related Issues (DRISTI), Proceedings published in International Journal of Computer Applications (IJCA), pp.20-25, 2012.

[22] H.O. Peitgen, H. Jürgens, D. Saupe, "Chaos and Fractals: New Frontiers of Science", Second Edition, pp89-90. Springer-Verlag New York, 2004.

[23] A. Danideh, R. Sadeghi-Fakhr and H. R. Hassani, "Wideband Co-Planar Microstrip Patch Antenna", Progress In Electromagnetics Research Letters, Vol. 4, pp. 81-89, 2008.

[24] A. Naghar, F. Falcone, A. Alejos, O. Aghzout and D. Alvarez," A Simple UWB Tapered Monopole Antenna with Dual WidebandNotched Performance by Using Single SRR-Slot and Single SRRShape.d Conductor-Backed Plane" ACES JOURNAL, Vol. 31, No.9,pp 1048-1055, September 2016.

[25] S. RafathAra And Dr. S. N. Mulgi," Multi Stepped Slotted Partial Ground Plane Dual Notched Ultra Wide Band Rectangular Microstrip Antenna", International Multidisciplinary Research Foundation (IMRF) : Vol. 5, Issue 1, pp 58-64, 2017. 